\title{
Analysis of in vitro apoptosis induced by virulent Korean isolate of classical swine fever virus in peripheral blood B cell line
}

\author{
Seon-Mi Kim, Seong-In Lim, Jae-Young Song, Bang-Hun Hyun* \\ Animal, Plant and Fisheries Quarantine and Inspection Agency, Anyang 430-757, Korea \\ (Received: April 24, 2012; Revised: November 5, 2012; Accepted: November 14, 2012)
}

\begin{abstract}
Classical swine fever (CSF) is a highly contagious disease among swine that has an important economic impact on worldwide. One clinical symptom of CSF is leukopenia, in particular lymphopenia, which is a characteristic event that occurs early in the course of CSF. Though lymphopenia associated with apoptosis, the pathogenic mechanism underlying the lymphopenia has not been well studied. To understand these mechanisms, we investigated the response of porcine B cell lines to infection with SW03, virulent strain isolated from swine tissue in Korea. This study demonstrated that SW03-infected L35 cell were induced apoptosis through the detection of activated caspase-3. In addition, SW03 infection leaded to alterations in pro-apoptotic, Bax, and anti-apoptotic, Bcl-xL proteins of Bcl-2 family. Our results would suggest that SW03-infected L35 cells induced apoptosis via intrinsic mitochondrial pathway.
\end{abstract}

Keywords : apoptosis, classical swine fever virus, lymphopenia, L35

\section{Introduction}

Classical swine fever virus (CSFV) belongs to the Pestivirus genus of the Flaviviridae family, along with bovine viral diarrhea virus (BVDV)-1, BVDV-2, and border disease virus. These viruses are closely related structurally, genetically, and antigenically. However, CSFV only infects swine and is highly contagious and often fatal to swine of all ages. It is characterized by pyrexia and severe leukopenia, as well as anorexia and diarrhea, in acute phase [9, 23]. Leukopenia could lead to immunosuppression and is a hallmark of certain virus infection, such as classical swine fever virus, Aujeszky's disease virus (ADV), foot-and-mouth disease virus (FMDV), avian influenza virus (AIV), canine distemper virus (CDV), African swine fever virus (ASFV), BVDV, human immunodeficiency virus (HIV), and measles virus $[10-12,16-18,21,23,25]$. The CSFV is known to have a particular affinity for cells of the immune system. All leukocyte population can be depleted during CSF, but B lymphocytes are particular sensitive [23]. Despite this knowledge, mechanism of B lymphocyte death has not been elucidated.

Apoptosis is a highly regulated mechanism of programmed cell death that plays important biological roles in the development and homeostasis of cell populations. It also constitutes a basic antiviral mechanism that limits viral replication and spread by inducing the suicide of infected cells. Apoptotic cells are rapidly phagocytosed, which leads to the presentation of viral antigens and the subsequent induction of an efficient immune response $[9,15,17]$. It can be induced via two well-known pathways. The one is the intrinsic pathway involves an alteration of the mitochondrial membrane potential. The other is the extrinsic pathway is characterized by interaction of ligands with death receptors [7]. In this study, we aimed to analyze mechanism behind this CSFVinduced lymphopenia. This study investigate whether SW03 strain [2], virulent CSFV strain isolated from CSFV-infected porcine in 2003, infected in porcine peripheral blood lymphocyte cell line, L35, if so which the cellular mechanism of SW03-infected L35 cell is used. Understanding the signal pathways elicited by SW03 infection will contribute valuable information about the pathogenesis of CSFV.

\section{Materials and Methods}

\section{Cells, viruses, and antibodies}

The $\mathrm{L} 35$ cell line that is derived from porcine peripheral B cell line [1] was maintained in RPMI1640 supplemented with $10 \%$ fetal bovine serum (FBS), glutamate, $1 \mathrm{x}$ antibiotics, and 2-mercaptomethanol at $37^{\circ} \mathrm{C}$ in an atmosphere containing $5 \%$ $\mathrm{CO}_{2}$. The SW03 strain is virulent CSFV strain isolated from CSFV-infected pigs in Korea [2].

\section{Cell viability}

To investigate the differences in the cellular response to infection with virulent strain, porcine L35 cells infected with CSFV at MOI of 0.7 and plated in 96-well flat-bottom tissue

*Corresponding author

Tel: +82-31-463-4568, Fax: +82-31-463-4565

E-mail: hyunbh@korea.kr 
culture plates. After cells were incubated for 24, 48, 72, and $96 \mathrm{~h}$ at $37^{\circ} \mathrm{C}$ in an atmosphere containing $5 \% \mathrm{CO}_{2}$, aseptically added alamarBlue solution (DAL1100; Biosource, USA) in an amount equal to $10 \%$ of the culture volume and the cultures were incubated for an additional $18 \mathrm{~h}$ at $37^{\circ} \mathrm{C}$. Absorbance was measured at 570 and $600 \mathrm{~nm}$ using the microplate reader (Tecan, Switzerland). This system incorporates an oxidation-reduction (redox) indicator that both fluoresces and changes color in response to a chemical reduction of the growth medium resulting from cell growth. We used this system to calculate the percent difference in reduction between infected and control cells in cytotoxicity assays.

\section{CSFV infection in $\mathbf{L 3 5}$ cells}

In order to investigate whether virulent CSFV strain infected in B cell line, L35 cells infected with CSFV at MOI of 0.35 . After $72 \mathrm{~h}$ post infection of SW03, cells were attached the slide glass. And then cells were washed with phosphate-buffered saline (PBS), and fixed with $4 \%$ paraformaldehyde for $15 \mathrm{~min}$ at room temperature, and air dry. The slide glass was incubated with CSFV E2 (gp55) monoclonal antibody LOM1 (JBT, Korea) for $2 \mathrm{~h}$ at $37^{\circ} \mathrm{C}$. After being washed, the slide was incubated with anti-mouse-FITC for $1 \mathrm{~h}$ at room temperature. The slides were washed and observed stained L35 cells using fluorescence microscope.

\section{Western blot analysis}

For western blot analysis, L35 cells in $25-\mathrm{cm}^{2}$ flasks infected with SW03 at MOI 0.35. CSFV-infected cells were incubated at $37^{\circ} \mathrm{C}$ in an atmosphere containing $5 \% \mathrm{CO}_{2}$ for 24, 48, 72, and 96 h. Harvested cells were lysed with RIPA buffer (100 mM Tris-HCl (pH 7.6), $5 \mathrm{mM}$ EDTA, $50 \mathrm{mM}$ $\mathrm{NaCl}, 0.5 \% \mathrm{NP}-40$, and $0.5 \% \mathrm{Na}$ deoxycholate containing a protease inhibitor cocktail solution). Total lysates were prepared and analyzed for expression of apoptosis-related proteins. Five microgram of the total lysates were loaded onto an SDS-PAGE gel and blotted on to nitrocellulose membranes. The membrane was blocked for $1 \mathrm{~h}$ at room temperature in 2\% blocking buffer (RPN2135; GE Healthcare, UK) and then incubated with antibodies against Bcl-xL (\#2764; Cell Signaling Technology, USA), Bax (625102; Biolegend, USA), caspase 3 (\#9662, Cell Signaling Technology), cytochrome c (556433; BD transduction laboratories, USA) and anti- $\beta$ actin (DB070; DeltaBiolab, USA) according to the manufacturer's instructions. Each membrane was washed with $0.1 \%$ TTBS and incubated with the secondary antibody, which was then developed via the chemiluminescence method following the manufacturer's protocol (RPN2135, ECL Advance Western Blotting Detection Kit; GE Healthcare).

\section{Results}

SW03 infection leads to the cytotoxicity of L35 cells in a time-dependent manner

To determine whether or not cytotoxicity was induced by
A

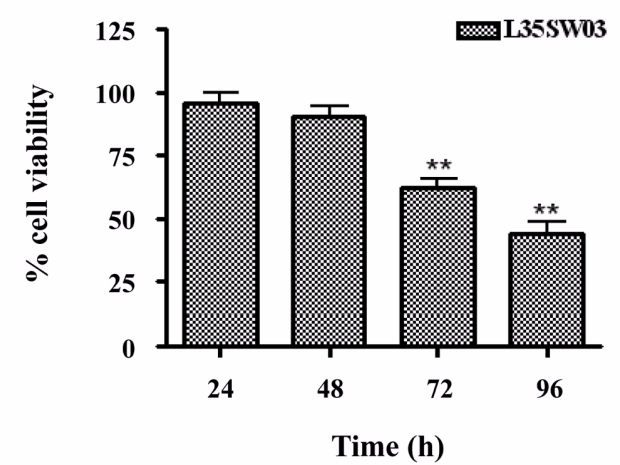

B

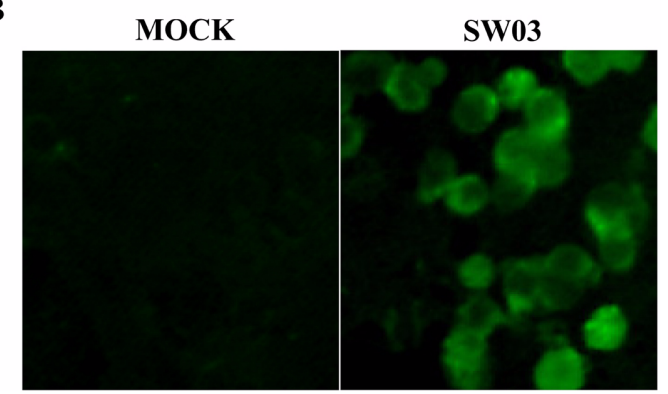

Fig. 1. Effects of cytotoxicity due to SW03 infection in porcine peripheral cell line, L35. (A) SW03-induced viability of L35 cells. We performed cell viability test using alamarBlue assay, described in the methods section. The graph shown represents an $n=3$ per experiment. (B) The CSFV antigen E2 was detected in SW03-infected L35 cells by immunofluorescence assay (IFA). After infection with SW03, cells were fixed and incubated with the CSFV E2 (gp55) monoclonal antibody.

SW03 infection, L35 cells were cultured in both the absence and presence of CSFV for 24, 48, 72, and $96 \mathrm{~h}$. Cell viability was assessed by alamarBlue assay in each time point. The viability of SW03-infected L35 cells denotes the decrease in a time-dependent manner, as shown in Fig. 1A. In order to investigate whether CSFV infection induced in B cell line, we infected with CSFV in L35 cells. After 3 days infection, these cells incubated with CSFV E2 (gp55) monoclonal antibody LOM1 (JBT, Korea). We detected E2 in CSFV-infected each cell line through fluorescence Fig. 1B.

Expression of apoptotic proteins, caspase-3 in SW03infected $\mathbf{L 3 5}$ cells

Through the cell viability test, we investigated cell death during SW03 infection. To identify the type of SW03induced cell death, we examined the alteration in the levels of several apoptosis-related proteins by western blot analysis. An important regulatory step in apoptotic processes is the activation of caspases. Therefore, we investigated the activation of the caspase-3. In our experiment, we used a caspase- 3 antibody that detected the endogenous levels of full length caspase-3 $(35 \mathrm{kDa})$ as well as the large fragment of caspase-3 


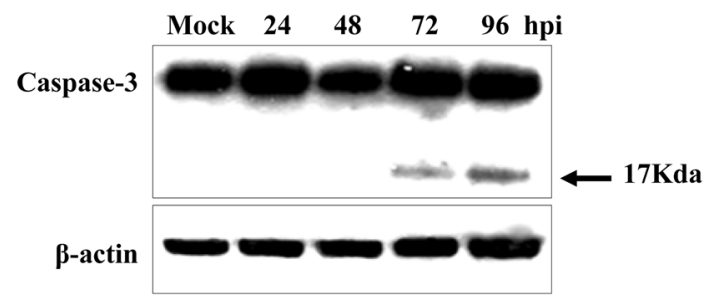

Fig. 2. SW03 infection induces activation of caspase-3 in L35 cells. Cells were infected with SW03 or mock infected. Cells were harvested for $24,48,72$ or $96 \mathrm{~h}$ post infection, and the lysates were subjected to western blotting with antibody to caspase-3. $\beta$-actin was used for loading control.

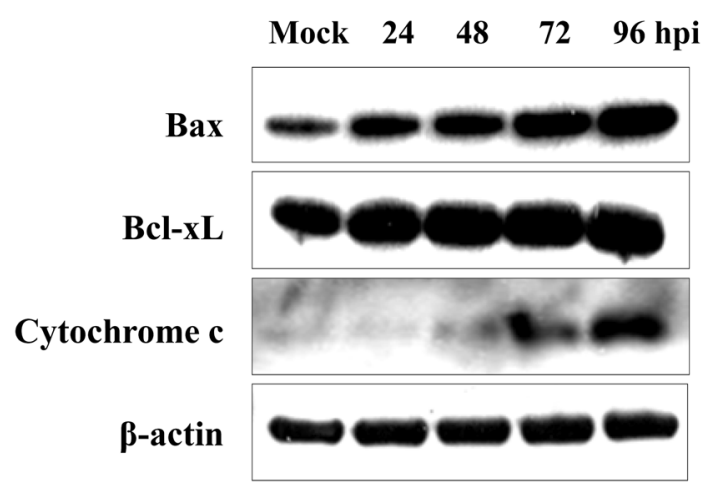

Fig. 3. Western blot analysis of apoptotic proteins in SW03infected cells. L35 cells were infected with SW03 and mock infected. Infected L35 cells were harvested at 24, 48, 72 or $96 \mathrm{~h}$ post infection. Western blot analysis was performed using primary antibodies to Bcl-xL, Bax, and cytochrome c.

$(17 \mathrm{kDa})$ that results from its cleavage. We observed activated caspase-3 form after $72 \mathrm{~h}$ post-infection in SW03infected L35 cells (Fig. 2). Our results indicated that infection of CSFV led to induction of apoptosis via the caspasesdependent pathway on B cell line.

Expression of apoptotic proteins, Bcl-2 family and release of cytochrome $c$ in CSFV-infected L35 cells

To demonstrate the relation to which apoptotic pathway may be induced after CSFV infection in L35 cells, we examined the change of Bcl-2 family proteins expression level. SW03-infected L35 cells were harvested 24, 48, 72, and $96 \mathrm{~h}$ after infection and subjected to western blot using anti-Bax, anti-Bcl-xL, anti-cytochrome $\mathrm{c}$ antibodies. Bcl-xL protein, an anti-apoptotic protein, levels keep increase in SW03-infected L35 cells compared to mock-infected cells. Bax protein, proapoptotic protein, levels increased in a time-dependently. And we observed the release of cytochrome c from mitochondria into the cytosol using anti-cytochrome c directed against cytosolic cytochrome c (Fig. 3). Our studies present that CSFV infection cause an alteration in Bcl-2 family protein and release of cytochrome c. In addition, these results suggest that CSFV-induced apoptosis mediated via the intrinsic pathway.

\section{Discussion}

The reduction in leukocyte numbers, lymphocyte activation and function following virulent CSFV infection are impaired decreasing antibody production and host defences $[13,22]$. During CSFV infection, all leukocytes have been depleted, B lymphocytes of them are particularly susceptible $[8,22-24,26]$. We observed induction of leukopenia for 5 to 18 day after infection of SW03 in pigs and we investigated that even if avirulent vaccine strain infected, leukopenia induced for 4 to 6 day (data not shown). We ascertained that L35 cell line infected with SW03 strain through immunofluorescence assay and identified that SW03-infected L35 cells decreased viability. So we confirmed type of cell death caused by SW03 strain infection through the activation of caspases; an important regulatory factor in apoptotic process $[3,4,9,15]$. It has been known that caspase- 3 is one of the key executioners of apoptosis. So we detected an active form of caspase-3 in SW03-infected L35 cell line by western blot analysis. This result correspond with reports that the transcriptional responses of caspases- 3 to CSFV infection were increased by about 4-fold [22] and the destruction of leukocytes following CSFV infection is largely associated with apoptosis in thymus, spleen, lymph nodes and bone marrow $[19,20,23]$. Consequently, our data suggest that the mechanism underlying the induction of lymphopenia following CSFV infection have related to apoptosis.

Following the signal pathway influenced by CSFV, we investigated change of Bcl-2 family protein related with apoptosis. The main function of $\mathrm{Bcl}-2$ proteins is to regulate cytochrome $\mathrm{c}$ release. Cytochrome $\mathrm{c}$ is released from mitochondria into cytosol in response to death signals and released cytochrome $\mathrm{c}$ activated caspase cascade. This is intrinsic apoptotic pathway, which is induced by a various apoptotic stimuli signals that cause an imbalance of the Bcl-2 family proteins, such as Bcl-2, Bcl-xL, Bax, and Bid in mitochondria. $[9,14,15,22]$. Several viruses have been reported to mediate apoptosis through the intrinsic apoptotic pathway [5, 6]. However, CSFV-induced apoptotic pathway has not been clear. Therefore we identified change of Bax and Bcl-xL expression levels and the release of cytochrome c from mitochondria into the cytosol in SW03-infected L35 cells. These results are consistent with those of previous studies that involve a number of other viruses $[5,6]$.

In conclusion, our results suggest that CSFV infection could induce apoptosis through mitochondrial-mediated pathway in porcine peripheral blood B cell line.

\section{References}

1. Bonenfant C, Vallée I, Sun J, Brossay A, Thibault G, Guillaumin JM, Lebranchu Y, Bardos P, Butler JE, Watier H. Analysis of human CD4 T lymphocyte proliferation induced by porcine lymphoblastoid B cell lines. Xenotransplantation 2003, 10, 107-119.

2. Cha SH, Choi EJ, Park JH, Yoon SR, Kwon JH, Yoon 
KJ, Song JY. Phylogenetic characterization of classical swine fever viruses isolated in Korea between 1988 and 2003. Virus Res 2007, 126, 256-261.

3. Chowdhury I, Tharakan B, Bhat GK. Caspases - an update. Comp Biochem Physiol B Biochem Mol Biol 2008, 151, 10-27.

4. Cohen GM. Caspases: the executioners of apoptosis. Biochem J 1997, 326 (Pt 1), 1-16.

5. Deng L, Adachi T, Kitayama K, Bungyoku Y, Kitazawa S, Ishido S, Shoji I, Hotta H. Hepatitis C virus infection induces apoptosis through a Bax-triggered, mitochondrionmediated, caspase 3-dependent pathway. J Virol 2008, 82, 10375-10385.

6. Ding L, Xu X, Huang Y, Li Z, Zhang K, Chen G, Yu G, Wang Z, Li W, Tong D. Transmissible gastroenteritis virus infection induces apoptosis through FasL- and mitochondria-mediated pathways. Vet Microbiol 2012, 158, $12-22$.

7. Galluzzi L, Joza N, Tasdemir E, Maiuri MC, Hengartner M, Abrams JM, Tavernarakis N, Penninger J, Madeo F, Kroemer G. No death without life: vital functions of apoptotic effectors. Cell Death Differ 2008, 15, 1113-1123.

8. Jamin A, Gorin S, Cariolet R, Le Potier MF, KuntzSimon G. Classical swine fever virus induces activation of plasmacytoid and conventional dendritic cells in tonsil, blood, and spleen of infected pigs. Vet Res 2008, 39, 7.

9. Johns HL, Bensaude E, La Rocca SA, Seago J, Charleston B, Steinbach F, Drew TW, Crooke H, Everett H. Classical swine fever virus infection protects aortic endothelial cells from pIpC-mediated apoptosis. J Gen Virol 2010, 91, 1038-1046.

10. Jungi TW, Schweizer M, Perler L, Peterhans E. Supernatants of virus-infected macrophages prime uninfected macrophages for lipopolysaccharide-induced apoptosis by both an interferon-dependent and an independent mechanism. Pathobiology 1999, 67, 294-297.

11. Karalyan Z, Zakaryan H, Arzumanyan H, Sargsyan K, Voskanyan H, Hakobyan L, Abroyan L, Avetisyan A, Karalova E. Pathology of porcine peripheral white blood cells during infection with African swine fever virus. BMC Vet Res 2012, 8, 18.

12. Koga R, Ohno S, Ikegame S, Yanagi Y. Measles virusinduced immunosuppression in SLAM knock-in mice. J Virol 2010, 84, 5360-5367.

13. Lee WC, Wang CS, Chien MS. Virus antigen expression and alterations in peripheral blood mononuclear cell subpopulations after classical swine fever virus infection. Vet Microbiol 1999, 67, 17-29.

14. Li P, Nijhawan D, Budihardjo I, Srinivasula SM,
Ahmad M, Alnemri ES, Wang X. Cytochrome c and dATP-dependent formation of Apaf-1/caspase-9 complex initiates an apoptotic protease cascade. Cell 1997, 91, 479489.

15. Luo X, Budihardjo I, Zou H, Slaughter C, Wang $\mathbf{X}$. Bid, a Bcl2 interacting protein, mediates cytochrome c release from mitochondria in response to activation of cell surface death receptors. Cell 1998, 94, 481-490.

16. Page GR, Wang FI, Hahn EC. Interaction of pseudorabies virus with porcine peripheral blood lymphocytes. J Leukoc Biol 1992, 52, 441-448.

17. Pillet S, von Messling V. Canine distemper virus selectively inhibits apoptosis progression in infected immune cells. J Virol 2009, 83, 6279-6287.

18. Sammicheli S, Dang VP, Ruffin N, Pham HT, Lantto R, Vivar N, Chiodi F, Rethi B. IL-7 promotes CD95-induced apoptosis in B cells via the IFN- $\gamma /$ STAT1 pathway. PLoS ONE 2011, 6, e28629.

19. Sánchez-Cordón PJ, Romanini S, Salguero FJ, Núñez A, Bautista MJ, Jover A, Gómez-Villamos JC. Apoptosis of thymocytes related to cytokine expression in experimental classical swine fever. J Comp Pathol 2002, 127, 239-248.

20. Sato M, Mikami O, Kobayashi M, Nakajima Y. Apoptosis in the lymphatic organs of piglets inoculated with classical swine fever virus. Vet Microbiol 2000, 75, 1-9.

21. Schobesberger M, Summerfield A, Doherr MG, Zurbriggen A, Griot C. Canine distemper virus-induced depletion of uninfected lymphocytes is associated with apoptosis. Vet Immunol Immunopathol 2005, 104, 33-44.

22. Shi Z, Sun J, Guo H, Tu C. Genomic expression profiling of peripheral blood leukocytes of pigs infected with highly virulent classical swine fever virus strain Shimen. J Gen Virol 2009, 90 (Pt 7), 1670-1680.

23. Summerfield A, Knötig SM, McCullough KC. Lymphocyte apoptosis during classical swine fever: implication of activation-induced cell death. J Virol 1998, 72, 1853-1861.

24. Susa M, König M, Saalmüller A, Reddehase MJ, Thiel HJ. Pathogenesis of classical swine fever: B-lymphocyte deficiency caused by hog cholera virus. J Virol 1992, 66, 1171-1175.

25. Uiprasertkul M, Kitphati R, Puthavathana P, Kriwong R, Kongchanagul A, Ungchusak $\mathrm{K}$, Angkasekwinai S, Chokephaibulkit K, Srisook K, Vanprapar N, Auewarakul P. Apoptosis and pathogenesis of avian influenza A (H5N1) virus in humans. Emerg Infect Dis 2007, 13, 708-712.

26. von Freyburg M, Ege A, Saalmüller A, Meyers G. Comparison of the effects of RNase-negative and wild-type classical swine fever virus on peripheral blood cells of infected pigs. J Gen Virol 2004, 85 (Pt 7), 1899-1908. 